\title{
O desenvolvimento mais sustentável da região amazônica: entre (muitas) controvérsias e o caminho possível*
}

\author{
Alfredo Kingo Oyama Homma ${ }^{1}$ \\ Antônio José Elias Amorim de Menezes² \\ Carlos Augusto Mattos Santana ${ }^{3}$ \\ Zander Navarro ${ }^{4}$
}

\begin{abstract}
Resumo
A Amazônia sempre despertou grande interesse da humanidade. Nas últimas décadas esse interesse aumentou substancialmente em virtude de crescentes preocupações com a sustentabilidade ambiental e os riscos impostos pelas mudanças climáticas. Esse contexto, juntamente com o baixo nível socioeconômico da população amazônica, o reduzido aproveitamento do potencial produtivo local e a intensa depredação do meio ambiente requer a definição urgente de um caminho possível de desenvolvimento mais sustentável para a região. 0 artigo busca contribuir com esse desafio. Nesse sentido, procura extrair lições de propostas potenciais que têm sido apresentadas para atingir o desmatamento zero e melhorar as condições de vida da população regional, por exemplo, "floresta em pé", extrativismo vegetal, bioeconomia e a riqueza da biodiversidade. Além disso, considera as diferentes realidades existentes na região, as políticas e marcos regulatórios em vigor, o estoque tecnológico disponível, a disponibilidade de assistência técnica, as experiências de desenvolvimento, e a heterogeneidade estrutural, socioeconômica e produtiva dos estabelecimentos rurais. Argumenta-se que a dimensão e a pobreza da região, a heterogeneidade do bioma, a especificidade de cada Estado com sua história, economia, aspectos sociais e políticos recomendam tratamento diferenciado. Ademais, advoga-se que o aumento sustentável da produtividade agrícola, a domesticação dos recursos da biodiversidade, o nivelamento tecnológico, a expansão da piscicultura, a aceleração da transição florestal e o aumento da presença do Estado na região amazônica para coibir os ilícitos deveriam ser parte da estratégia a seguir.
\end{abstract}

Palavras-chave: Amazônia, meio ambiente, sustentabilidade, mitos, problemas, soluções, desafios.

\section{The more sustainable development of the Amazon region: between (many) controversies and the possible path}

\begin{abstract}
The Amazon has always raised great interest from humanity. In the last decades, this interest has increased substantially due to growing concerns about environmental sustainability and the risks posed by climate change.

* Este artigo é parte do projeto apoiado pela Empresa Brasileira de Pesquisa Agropecuária (Embrapa), intitulado "Transformações recentes na agricultura amazônica: o caso do estado do Pará". Agradecimentos são devidos a Evaristo Eduardo de Miranda (e à Embrapa Territorial) e a Roni de Azevedo, Ronaldo Dias Castro, Raimundo Cosme de Oliveira Júnior, Lucieta Guerreiro Martorano, Vivian Dagnesi Timpani e Daniel Mangas, todos pesquisadores da Embrapa Amazônia Oriental, pelo apoio logístico à pesquisa no Nordeste, Sudeste e Baixo Amazonas Paraense. Ressalte-se, contudo, que os eventuais erros e o conteúdo argumentativo são de exclusiva responsabilidade dos autores.
\end{abstract}

${ }^{1}$ Doutor em Economia Rural (UFV). Pesquisador da Empresa Brasileira de Pesquisa Agropecuária - Embrapa Amazônia Oriental (Belém-PA). Professor do Programa de Pós-Graduação em Ciências Ambientais da Universidade do Estado do Pará (UEPA). Orcid: 0000-0003-0330-9858. alfredo.homma@embrapa.br

2 Doutor em Sistemas de Produção Agrícola Familiar (UFPel). Pesquisador da Empresa Brasileira de Pesquisa Agropecuária - Embrapa Amazônia Oriental (Belém-PA). Orcid: 0000-0002-3294-5354. antonio.menezes@embrapa.br

3 Doutor em Economia Agrícola (University of Minnesota). Pesquisador da Secretaria de Inteligência e Relações Estratégicas da Embrapa Sede (Brasília-DF). Orcid: 0000-0002-3430-0787. carlos.santana@embrapa.br

${ }^{4}$ Doutor em Sociologia (Universidade de Sussex, Inglaterra) e Pós-doutor em Ciência Política (MIT, EUA). Pesquisador da Secretaria de Inteligência e Relações Estratégicas da Embrapa Sede (Brasília-DF). Orcid: 0000-0003-3192-8656. z.navarro@uol.com.br 
This context, together with the low socioeconomic conditions of the Amazonian population, the reduced use of the local productive potential and the intense environmental depredation, requires an urgent definition of a possible more sustainable development path for the region. The article seeks to contribute to this challenge. In this regard, it draws lessons from potential proposals that have been presented to achieve zero deforestation and improve the living conditions of the regional population, for example, "standing forest", plant extractivism, bioeconomy and biodiversity wealth. In addition, it considers the different realities existing in the region, the policies and regulatory frameworks in force, the technological stock available, the availability of technical assistance, the development experiences, and the structural, socioeconomic and productive heterogeneity of rural establishments. It is argued that the size and poverty of the region, the heterogeneity of the biome, the specificity of each state with its history, economy, social and political aspects require different approaches. Furthermore, it is argued that the sustainable increase in agricultural productivity, the domestication of biodiversity resources, technological leveling, the expansion of fish farming, the acceleration of the forest transition and the increase of the State's presence in the Amazon region to curb illicit activities should be part of the strategy to follow.

Keywords: Amazon, environment, sustainability, myths, problems, solutions, challenges

\section{Introdução}

Historicamente, a Amazônia tem sido uma região de grande interesse para o Brasil e o mundo. Em face de sua extraordinária extensão, riqueza em recursos naturais e incomum especificidade social, associado a um relativo, mas ainda amplo, desconhecimento, a região sempre despertou não apenas a curiosidade, mas surpresas e alguma perplexidade. Notabilizada pela presença de povos indígenas (e suas inúmeras línguas distintas) e dominada pela floresta densa entrecortada pelo maior rio do mundo, ocupa em proporções variadas nove países da América do Sul, sendo dois terços do seu total de 6.4 milhões de quilômetros quadrados em território brasileiro. Se considerada apenas a parte nacional, a Amazônia seria maior do que a União Europeia e se constituiria no sétimo país em extensão. Abriga a maior floresta tropical do planeta e sua bacia hidrográfica se estende por $44 \%$ da superfície do continente, além de acumular notável riqueza em recursos de mineração e expressivo potencial hidroelétrico.

Agregue-se a esse imenso contexto socioambiental a quase infinita biodiversidade existente e são oferecidos, em consequência, todos os ingredientes para incentivar o desenvolvimento de diferentes interpretações, narrativas e teorias explicativas sobre o significado histórico da região e a exploração mais sustentável de suas potencialidades. Adicionalmente, ante tal complexidade, dimensão e profusão de aspectos, é inevitável que prosperem também infindáveis debates e polêmicas sobre as principais facetas que determinariam a sua essencialidade e o estado atual e o futuro da Amazônia.

No passado, o foco residia, sobretudo, nas comunidades originais (atualmente em torno de 350 mil indígenas distribuídos em 330 terras próprias), notadamente estudadas pela Antropologia. Mas o interesse geral e crescente sobre o bioma e sua população, no Brasil e alhures, vem sendo acelerado, sobretudo nos últimos trinta anos, em função de diversos vetores 
principais. Desde a emergência formal da noção de "sustentabilidade", conforme a famosa definição contida em Nosso futuro comum (BRUNDTLAND et al., 1987) e a gradual animação de forças sociais movidas por um olhar ambiental, à ampliação recente dos debates em decorrência das mudanças climáticas. Essas últimas são perspectivas que reforçaram a decisiva relação entre a floresta amazônica e o equilíbrio climático do planeta. No Brasil, em particular, vai sendo percebido um terceiro fator, igualmente crucial para a economia, que diz respeito ao regime de chuvas formado a partir da delicada combinação entre os fenômenos atmosféricos, a preservação da floresta e os indicadores pluviométricos das demais regiões em torno do bioma (NOBRE, 2014).

Esses aspectos, associados à preocupação com o aumento das queimadas e os indicadores alarmantes de desmatamento, particularmente no presente século, colocaram o foco sobre o "desenvolvimento sustentável da região amazônica" no topo das prioridades nacionais. Simultaneamente, ante tal proeminência, surgiram imensas dificuldades analíticas (incluindo aquelas de natureza política) para discutir o tema, pois avolumam-se as propostas para confrontar os dilemas, os impasses, os bloqueios e os desafios existentes. É assim em face da quase infinita complexidade a ser iluminada em todos os âmbitos. No plano político, como ilustração, há uma fração relevante das ações mais consequentes que demandaria a concordância dos demais países vizinhos que compartilham parte do bioma. Mas o chamado "Pacto Amazônico", assinado em 1978 por oito países da região, tem se mostrado, de fato, uma promessa anódina de cooperação. Ou então, como outro exemplo, nesse caso estritamente brasileiro, as nascentes da bacia hidrográfica, no lado direito do rio Amazonas, situam-se em regiões nacionais, onde a economia agropecuária vem se expandindo com rapidez, usando avidamente os recursos de água e terra (KINOSHITA, 2016). Trata-se de um descontrolado crescimento que poderá igualmente afetar o futuro próximo da região amazônica e, assim, como lidar com esses interesses aparentemente conflitantes?

São fatos que configuram um quadro geral extremamente multifacetado e problemático. E sob tal contexto, não deve surpreender que proliferem visões, controvérsias e até mitos, os mais diversos, em acordo com interpretações e as ideologias de seus proponentes. Ou inúmeras recomendações e argumentos que, à luz de evidências empíricas, não são realistas. Muitas são as vozes, por exemplo, que falam em "povos da floresta", certamente se referindo, em especial, às comunidades indígenas, mas também incluindo "povos tradicionais", "ribeirinhos" e outros grupos sociais vagamente identificáveis. Mas, se tomados os indicadores censitários, a região segue o padrão nacional e vai celeremente se tornando urbana - apenas um terço são moradores 
rurais, e esta proporção diminui a cada censo. Não está distante, portanto, o tempo sob o qual os "povos da floresta" estarão habitando as cidades da região.

Adicionalmente, embora persista uma nítida diversidade sociocultural e heterogeneidade econômico-produtiva no interior da região, em inúmeras esferas, comumente têm sido oferecidas grandiosas adjetivações para designar toda a Amazônia, como se esta fosse única e homogênea. Desde a promessa de vir a se tornar "o celeiro do mundo", conforme asseverou von Humboldt em 1800 ou, pelo contrário, "o inferno verde", na célebre expressão de Alberto Rangel (em 1904). Mas a região se tornou notória quando foi publicado em 1975 o livro A floresta amazônica: do inferno verde ao deserto vermelho? (GOODLAND e IRWIN, 1975), o qual causou intensa repercussão e inseriu o tema das queimadas e do desmatamento permanentemente na agenda mundial. Analisando-se esta prática do “(...) século XVIII até os dias atuais (julho de 2019), a área total desmatada, cartografada pelo Programa Prodes, do INPE, acumula uma superfície de $719.014 \mathrm{~km}^{2}$, equivalentes a $18,9 \%$ da parte florestal do bioma Amazônia e a $17,1 \%$ de sua extensão total" (MIRANDA et al., 2020b, p.2). Esta área seria superior às superfícies totais, conjuntamente, do Japão e da Alemanha, ${ }^{1}$ respectivamente, a terceira e a quarta economia do mundo.

Entre diversos contrastes, a região ostenta uma biodiversidade espetacular, cujas manifestações causam estupor. Habitam o bioma dez por cento de todas as espécies de plantas, das aves e de abelhas existentes no planeta, além de um quarto de todas as espécies de borboletas. Causou sensação internacional, por exemplo, a descoberta em 2013 de quinze novas espécies de aves, simultaneamente, fato raro que não ocorria há 140 anos (PIVETTA, 2013). Coexistem, contudo, com essa riqueza degradantes e inaceitáveis indicadores de pobreza que afetam a maior parte dos 27 milhões de habitantes da região amazônica. A história econômica do bioma registra a sucessão de diversos ciclos produtivos temporários. Do cacaueiro à seringueira, do pau rosa à castanha-do-pará, até chegar à exploração contemporânea de minérios, energia hidroelétrica, pecuária, madeira, grãos, pimenta, dendezeiro e, recentemente, do açaí e da soja, assim como o retorno da cacauicultura, entre outros que vêm se destacando em termos econômicos.

Por que esta natureza tão exuberante tem sido incapaz de se traduzir em bem estar para

\footnotetext{
1 Os cálculos da Embrapa Territorial (sediada em Campinas) indicam que a área total e protegida com cobertura vegetal no bioma amazônico totalizaria $84,1 \%$ do total $(25,1 \%$ em terras indígenas; $22,4 \%$ em áreas destinadas à preservação da vegetação nativa; $20,4 \%$ coberta com vegetação nativa em terras devolutas não cadastradas, e 16,2\% em unidades de conservação integral). Do restante, 2,1\% são cobertos pela hidrografia da região e 1,0\% com infraestrutura e outras destinações. Sobrariam $12,8 \%$ com uso agropecuário (10,5\% com pastagens e $2,3 \%$ destinados à agricultura).
} 
a população local ou enraizar um processo mais sustentado de desenvolvimento? Se cultivos originados na Amazônia, como a seringueira ou o cacaueiro, se tornaram "commodities" relevantes em outros locais, por que ainda não despontaram com maior desenvoltura econômica na região? São algumas das muitas perguntas principais que vêm motivando diversos estudiosos, governos e instituições e, como resultado, prospera atualmente uma longa lista de propostas, recomendações e supostos caminhos que poderiam promover o desenvolvimento social e mais sustentável da Amazônia.

Tais debates alcançaram recentemente um "ponto de ebulição", ampliando exponencialmente o rol de manifestações. Provavelmente, esse corte foi alcançado em função de duas justificativas principais. A primeira delas decorre do acúmulo de informações abrangentes sobre a Amazônia e suas relações com as mudanças climáticas e seus impactos em inúmeras esferas. Multiplicam-se as inquietações oriundas em distintos âmbitos e, desta forma, esta resultante vem sendo adensada social e politicamente, exercendo pressões contínuas sobre os governos brasileiros. A segunda razão é mais recente e emergiu no campo econômicofinanceiro, com a multiplicação de diversas intenções de agentes financeiros e governos de condicionar investimentos no Brasil a salvaguardas ambientais. ${ }^{2}$

Em decorrência dessas considerações, teria sido atingido um novo momento, do qual se torna inescapável, para os brasileiros envolvidos e suas instituições, implementar formas de ação mais consequentes, inicialmente para coibir formas de desmatamento e as queimadas e, desta forma, aquietar tais manifestações. Mas igualmente sob essa condensação de pressões, vem sendo demandado, em consequência, a elaboração de uma estratégia destinada a promover o desenvolvimento mais sustentável da região. Esta conjuntura dos anos imediatos é o pano de fundo do presente artigo.

Seguindo-se a esta Introdução, o artigo se estrutura em três seções. Ante o contexto geral sucintamente apontado, é esperado que inúmeras "leituras" e reflexões, além de propostas de mudança, sejam apresentadas por diferentes agentes interessados na Amazônia. São

\footnotetext{
${ }^{2}$ São inúmeras e crescentes as declarações de representantes do capital financeiro, especialmente aqueles ligados a bancos europeus e aos fundos de investimento, exigindo maiores garantias ambientais de seus interlocutores no Brasil. Nesse sentido, foi relevante a manifestação de diversas empresas e investidores congregados no Conselho Empresarial Brasileiro para o Desenvolvimento Sustentável. Em comunicado de julho de 2020, manifestaram "preocupação com a percepção internacional negativa do Brasil em relação à Amazônia" e, entre outras medidas, pedem o fim do desmatamento ilegal (ver em https://cebds.org/). No mesmo mês, o presidente de um dos maiores bancos brasileiros foi categórico: “(...) O olhar europeu é rigoroso aí. Eles estão comprometidos com iniciativas sustentáveis (...) A Europa é um continente velho e rico. O dinheiro se acumulou durante anos, mas o propósito não é sempre o maior retorno no curto prazo, mas o melhor retorno com sustentabilidade ambiental (...) Não estamos falando em preservar a biodiversidade de uma maneira romântica, mas em ter uma agenda de desenvolvimento com preservação" (Sérgio Rial, presidente do Santander, Folha de São Paulo, 20 de julho de 2020, grifo acrescido).
} 
interpretações que vêm se intensificando, aproximadamente, nos últimos trinta anos, mas particularmente nesse século, porque o tema das mudanças climáticas vem exigindo absoluto destaque para a floresta amazônica e seus diversos "serviços ambientais". Como parte considerável desta problemática nem sempre é nitidamente percebida por todos, essas narrativas e suas decorrentes "propostas de ação" têm estimulado diversas controvérsias. Assim, a segunda seção do artigo, após esta Introdução, resume e discute alguns temas que têm gerado disputas analíticas ou polêmicas entre diversos atores sociais e agentes econômicos interessados.

Ante o variado quadro de vias sugeridas para promover o desenvolvimento mais sustentável da região, a terceira seção propõe, como seu pressuposto fundador, a necessidade de escapar, com urgência, da polaridade vigente que antagoniza, de um lado, uma estratégia exclusivamente ambiental e, de outro, em oposição, um roteiro essencialmente produtivo e econômico. Esta antinomia, que já se estende por muitos anos sem encontrar solução convergente, está exigindo que seja apresentada uma proposta realista, radicalmente empírica e centrada na história da região ${ }^{3}$. Seria o caminho possível, como é aqui intitulado, pois propõe iniciativas que já foram provadas em outros contextos, são lógicas próprias das realidades da região e, em especial, são concretamente viáveis - atualmente, não em um futuro indefinível. As Conclusões, no final, sintetizam algumas das principais reflexões do artigo.

\section{Controvérsias sobre a Amazônia}

Discute-se a seguir um conjunto de temas que vêm povoando os debates sobre a "problemática amazônica". Provavelmente são os mais assíduos na discussão pública, e focos que normalmente estimulam controvérsias, às vezes acirradas, entre os envolvidos no debate. São apresentados abaixo esquematicamente, seguidos por comentários que pretendem oferecer esclarecimentos adicionais a respeito, com o intuito de construir pontes de entendimento que possam contribuir para a formulação de uma estratégia de desenvolvimento mais sustentável

\footnotetext{
${ }^{3}$ Ismael Nobre e Carlos Nobre propuseram uma "terceira via amazônica". Seria uma estratégia sob a qual seria utilizado “(...) todo o conhecimento propiciado pelas ciências, pela tecnologia e pela inovação e planejamento estratégico para o florescimento de uma bioeconomia baseada na ideia de uma floresta em pé com os rios fluindo, valorização da biodiversidade e do trabalho sustentável das comunidades locais" (NOBRE e NOBRE, 2019, p. 11). Considerando-se a solidez científica dos autores, trata-se de uma proposta surpreendentemente romântica, prenhe de idealismo e, por isso, futurista. Tão distante temporalmente de concretização, à luz das condições realmente existentes, que se torna absolutamente utópica.
} 
para a Amazônia.

O que significa "região amazônica"? É o ponto de partida e requer ampla concordância entre os diversos entes envolvidos, sejam eles os estados e suas instituições e espaços de decisão e, em especial, o Governo Federal e seus diversos tentáculos de ação operacional nesta parte do Brasil. Seria ideal que os demais países que integram o bioma amazônico também subscrevessem essa sugestão espacial-conceitual. Desde 1953 existe, por exemplo, a definição de "Amazônia Legal", quando a região era ainda escassamente habitada e vivia em sonolência produtiva. Por que ainda se mantém essa conceituação? Além disso, se utiliza, com frequência, a noção de "região norte", formada pelos estados constituintes. Reflete o federalismo brasileiro e, como tal, não pode ser abolida. Esse olhar conceitual múltiplo e relativamente contraditório sobre a região não é tema irrelevante, bastando lembrar que somente o conhecimento aprofundado sobre uma Amazônia que, na realidade, é fortemente heterogênea, mas com seus contornos definidos e utilizados por todos, é que poderá permitir o desenho de ações e políticas igualmente diferenciadas.

Argumenta-se nesse artigo que a designação ideal para lidar com o tema seria formalizar administrativamente aquela relativa ao "bioma amazônico" $(4.199 .249$ km², ocupando 49,3\% do território brasileiro). A razão principal é de relativa obviedade. Se a "problemática amazônica" tem atualmente como cerne um "foco ambiental" que se tornou obrigatório, então o conceito ecológico de bioma se torna o mais apropriado entre todos. O Brasil deveria instituir a decisão de assim proceder em relação a esta "questão nacional", sem nenhum prejuízo, evidentemente, das prerrogativas decisórias de cada estado integrante. Mas, ao mesmo tempo, esta uniformidade classificatória centrada no bioma (também formalizada no Código Florestal) permitirá ao governo central e seus entes subnacionais proporem uma série de ações (com diversos propósitos) que passariam então a seguir, obrigatoriamente, os ditames assentados em uma lógica ambiental que se articularia com os demais âmbitos. E, assim, gradualmente uma convergência entre "ambiente" e outros condicionantes - como os produtivos - poderia ser concretizada.

Investimentos em logística, por exemplo, não poderiam mais seguir a armadura convencional do passado. Precisariam integrar logicamente os mais variados determinantes ambientais para se tornarem realidade, muito além das normas hoje vigentes. Sem muitos comentários a respeito, considere-se a abertura de estradas como uma reveladora ilustração. A abertura da "rodovia diagonal" BR-364 (Cuiabá-Porto Velho), por exemplo, nos legou uma história de devastação florestal que ativou até mesmo, na década de 1980, o "painel de inspeção" 
do Banco Mundial, um dos financiadores da estrada. Tal experiência deveria ter produzido um aprendizado para outras obras, ora em conclusão na região amazônica, como a BR-163 (Cuiabá a Santarém) e a BR-319 (Porto Velho a Manaus). Sem uma efetiva e abrangente governança, realmente adequada de proteção à floresta circundante, a primeira irá afetar diretamente uma enorme área ainda sob cobertura florestal no oeste paraense (FEARNSIDE, 2007), enquanto a segunda poderá ser a "pá de cal" para o futuro próximo do bioma amazônico, sem uma adequada estratégia da relação entre a rodovia e o coração florestal do estado do Amazonas. São muitos os outros exemplos, como mineração ou hidroelétricas.

Como se observa na Figura 1, reforçando esta discussão sobre o significado da expressão "região amazônica", os estados que integram o bioma, total ou parcialmente, apresentam indicadores estatísticos bastante distintos de cobertura vegetal. A maior parte do Maranhão, Tocantins, o leste do Pará e quase a metade do norte do Mato Grosso já foram fortemente desmatados e observa-se atualmente um "movimento de pinça" em direção ao interior do Pará.

Figura 1. Área florestal do bioma Amazônia e as áreas exploradas em cada estado

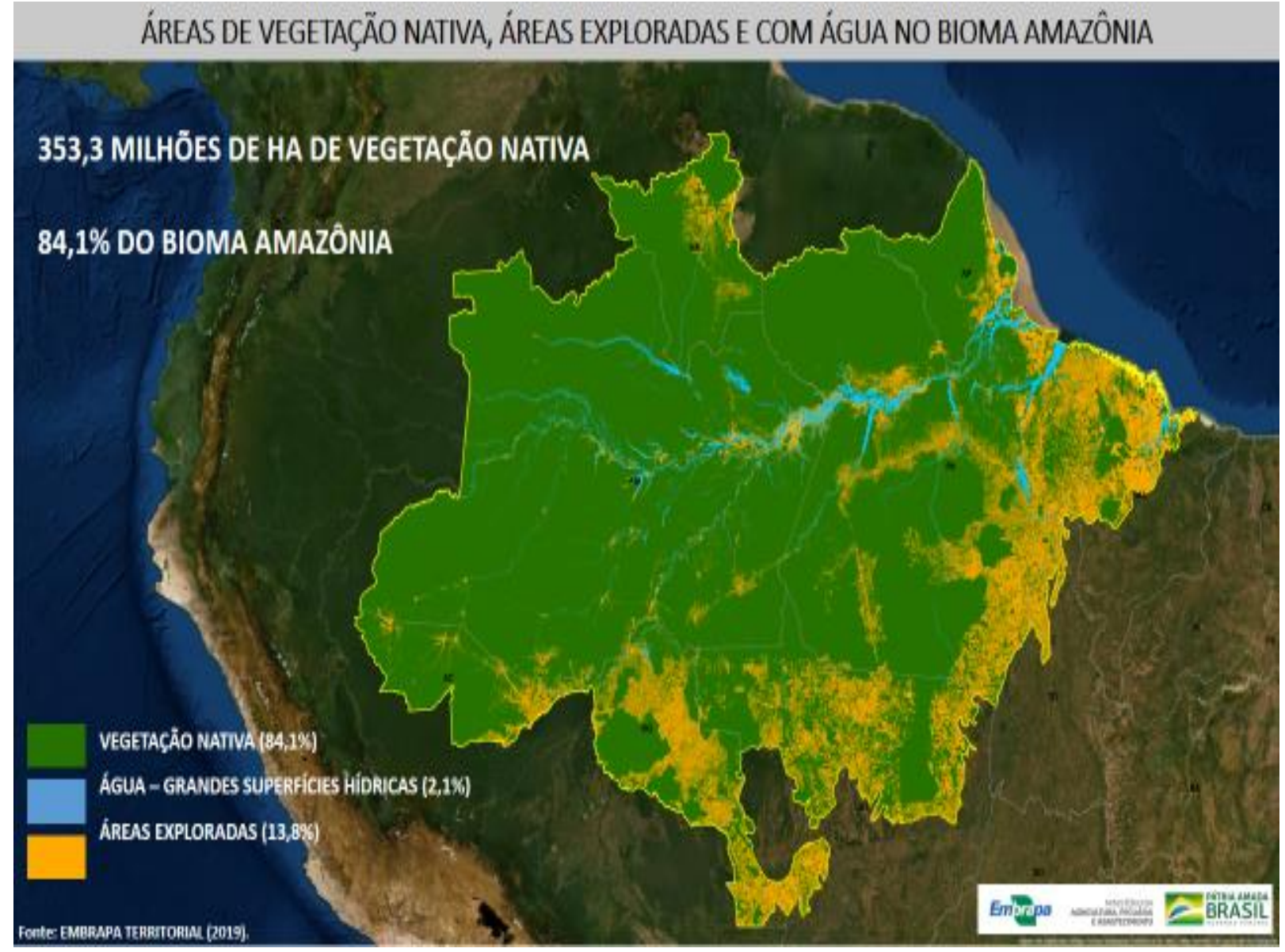

Fontes: Produzida pela Embrapa Territorial através de cálculos realizados por geoprocessamento, no sistema de informação geográfica ArcGIS 10.7 (ESRI, 2020), utilizando o sistema geodésico de referência SIRGAS 2000 e a projeção adotada pelo IBGE (IBGE, 2014). ESRI. ArcGIS 10.7. 2020. Sistema disponível no endereço: http://www.esri.com/software/arcgis/arcgis-for-desktop; IBGE. Estrutura Territorial. 2014. Disponível em: https://www.ibge.gov.br/geociencias/organizacao-do-territorio/estrutura-territorial.html. 
Desta forma, considerando-se o bioma como um todo, o termo mais preciso para caracterizá-lo é a sua forte heterogeneidade, não apenas em termos da existência ou não da cobertura vegetal, mas igualmente em relação aos tipos de vegetação existentes, os quais variam de forma significativa. Igualmente, o mapa (Figura 1) permite visualizar, e no Quadro 1 verificase a respectiva participação absoluta e relativa, que o bioma engloba uma pequena parte do Tocantins (8,9\%), pouco mais da metade do Mato Grosso (53,5\%), um terço do Maranhão (34,8\%) e, no restante, engloba totalmente os estados do Pará, Amazonas, Roraima, Acre, Amapá e quase a totalidade de Rondônia (99,8\%).

A heterogeneidade estrutural que identifica o bioma amazônico evidencia-se quando se identificam as proporções de cobertura florestal existentes. Aqui existe uma dificuldade metodológica, não discutida em detalhes nesse texto, sobre a definição de "floresta". Sem nenhuma problematização, será seguido aqui o estipulado pelo "Programa de Monitoramento da Floresta Amazônica Brasileira por Satélite" (PRODES), o qual define desmatamento (a "não floresta") como a "conversão por supressão de áreas de fisionomia florestal primária por ações antropogênicas" (INPA, 2019, p. 8).

Quadro 1. Participação absoluta e relativa do bioma Amazônia em cada Estado. Áreas florestais de acordo com o PRODES e áreas intactas de floresta.

\begin{tabular}{|c|r|r|r|r|r|r|}
\hline UF & $\begin{array}{c}\text { Área do } \\
\text { Estado } \\
\left(\mathrm{km}^{2}\right)\end{array}$ & $\begin{array}{c}\text { \% do Estado } \\
\text { dentro do } \\
\text { Bioma }\end{array}$ & $\begin{array}{c}\text { Área do } \\
\text { Estado no } \\
\text { Bioma }\left(\mathrm{km}^{2}\right)\end{array}$ & $\begin{array}{c}\text { Área florestal } \\
\text { do PRODES } \\
\left(\mathrm{km}^{2}\right)\end{array}$ & $\begin{array}{c}\text { Área floresta } \\
\text { intacta } \\
\left(\mathrm{km}^{2}\right)\end{array}$ & $\begin{array}{c}\text { \% em relação } \\
\text { à área florestal } \\
\text { PRODES }\end{array}$ \\
\hline AM & 1.559 .147 & 100,0 & 1.559 .147 & 1.459 .745 & 1.417 .792 & 97,1 \\
\hline PA & 1.247 .955 & 100,0 & 1.247 .675 & 1.130 .555 & 858.518 & 75,9 \\
\hline MT & 903.202 & 53,5 & 483.432 & 433.966 & 254.222 & 58,6 \\
\hline RO & 237.765 & 99,8 & 237.277 & 211.345 & 117.350 & 55,5 \\
\hline RR & 224.301 & 100,0 & 224.301 & 161.605 & 149.531 & 92,5 \\
\hline AC & 164.124 & 100,0 & 164.124 & 163.941 & 140.545 & 85,7 \\
\hline AP & 142.829 & 100,0 & 142.829 & 113.376 & 109.798 & 96,8 \\
\hline MA & 331.937 & 34,8 & 115.644 & 102.503 & 25.251 & 24,6 \\
\hline TO & 227.720 & 8,9 & 24.822 & 22.667 & 2.305 & 10,2 \\
\hline Total & 5.038 .980 & --- & 4.199 .249 & 3.799 .702 & 3.075 .311 & 80,9 \\
\hline
\end{tabular}

Fonte: Produzida pela Embrapa Territorial através de cálculos realizados por geoprocessamento, no sistema de informação geográfica ArcGIS 10.7 (ESRI, 2020).

Essas áreas de cobertura variam entre o extremo da floresta ombrófila densa às áreas de tensão ecológica entre o cerrado e a floresta, mas ainda com predominância de fisionomia vegetal (Ibid, p. 13). As áreas de "floresta" foram cotejadas seguindo-se os critérios definidos pela Embrapa Territorial (ver a "fonte" no mapa), obtendo-se então os dados relativos à "floresta 
intacta" por estado. Como se nota, em Tocantins praticamente não existe mais tal cobertura na sua parte dentro do bioma. É também relativamente pequena no Maranhão e atinge apenas a metade em Mato Grosso e Rondônia. E no segundo maior estado brasileiro, o Pará, um quarto da cobertura florestal já teria sido desmatada. Esses dados, que retratam a situação existente, definem o ambiente a ser considerado na definição de ações estratégicas para o desenvolvimento mais sustentável da região.

O extrativismo nunca foi a solução. A criação de reservas extrativistas, uma iniciativa que se expandiu ao longo do tempo, sobretudo, depois do assassinato de Chico Mendes (1944) em 1988, tem sido uma das mais aplaudidas no contexto da preservação dos recursos florestais. Destaque-se, contudo, como regra geral, que o extrativismo pode ser viável somente em situações de mercado reduzido. Quando os mercados crescem, os agricultores são estimulados a expandir suas plantações e, ante o fato, acontece o colapso da atividade extrativa. Afinal, esta é a lição milenar decorrente do aprendizado extraído de mais de três mil plantas cultivadas e centenas de animais domesticados, em todo o mundo.

A economia extrativista é um ciclo no qual se tem a fase da expansão, depois a estabilização e finalmente o seu declínio. Simultaneamente, desenvolvem-se práticas de manejo e de domesticação de cultivos ou de criação, podendo evoluir até para a descoberta de sintéticos (borracha sintética, sucos artificiais, baunilha sintética, madeira plástica, fios industriais).

Para muitos produtos tipicamente extrativos da Amazônia já existe um conflito entre a oferta e a demanda, como ocorre com a castanha-do-pará, o açaí, a borracha, o tucumã, o pau rosa, o bacuri, o uxi, o puxuri, etc. No caso dessas plantas, é previsível o iminente esgotamento do extrativismo convencional para atender à demanda, sendo urgente desenvolver formas de manejo e plantios mais produtivos, além de promover a verticalização. Muitos produtos extrativos já foram ou estão sendo domesticados, como o cacaueiro, seringueira, urucuzeiro, guaranazeiro, cupuaçuzeiro, açaizeiro, jambu, etc. A insistência na narrativa do extrativismo vem se tornando perniciosa, pois irá manter o atraso tecnológico entre os produtores tradicionais que resistirem à modernização, caso surja uma oferta derivada de cultivos de melhor qualidade, maior produtividade e preços mais baixos.

Os recursos extrativos, quer sejam da flora ou da fauna, encontram-se dispersos na natureza, implicando em uma baixa produtividade da terra e da mão de obra. Dessa forma, são atividades que persistirão apenas na ausência de alternativas econômicas. É a desenvoltura dos mercados, de fato, que determina a duração do extrativismo. Caso se mantenha limitado, manterá tal prática. Se crescer, contudo, destruirá gradualmente esta antiga forma de produção 
de renda.

A "infinita riqueza" da biodiversidade amazônica. A frase espelha um fato inegável, conforme esboçado na Introdução. Evidências assistemáticas, organizadas cientificamente e disponíveis em abundante bibliografia, demonstram categoricamente a fabulosa riqueza potencial embutida nos recursos naturais da região amazônica. A crucial importância de aprofundarmos o conhecimento empírico do potencial específico da biodiversidade da região se acentua por não existir, no restante do planeta, nada comparável, em nenhum outro país ou continente. Portanto, são recursos potencialmente destinados a diversas formas de exploração econômica, com benefícios, igualmente potenciais, destinados à humanidade. O corolário é imediato e inegável: “(...) Utilizar insumos abundantes em sistemas extrativistas e agroflorestais e transformá-los em algo de valor, através da bioindústria de transformação, é a essência do que propomos para a Amazônia" (NOBRE e NOBRE, 2019, p. 19).

Mas, ante a verificação acima, uma polêmica decorre de duas perguntas práticas e imediatas: como e quando? Quais são os caminhos para estimular formas de exploração econômica desses recursos disponíveis que, de fato, produzem riqueza e, ainda mais, possam se constituir em riqueza inclusiva? Que vá além, por exemplo, da exploração mineral, que transporta a vasta maioria da riqueza retirada para outras partes do Brasil ou para fora do país. Ainda não existem abrangentes respostas concretas e estratégicas para esta primeira pergunta - como gerar riquezas para a região e sua população? O caminho possível que é proposto na terceira seção desse artigo sugere que esta via existe, mas como qualquer almejado processo de "desenvolvimento", é também incerto e, em geral, de médio a longo prazo.

Quando ocorrerá a materialização de diferentes, múltiplas e consequentes formas de atividade econômica, que sejam adequadas aos imperativos ambientais e que se traduzam em produção de valor para a sociedade regional? Esta é a outra pergunta decisiva porque a sociedade amazônica, como o restante do país, é profundamente desigual, com a vastíssima maioria da população ostentando padrões de pobreza que estão entre os mais baixos do Brasil usualmente, a maior parte de seus municípios ostentam IDH(s) muito baixos. Trata-se de cidadãos que não podem esperar por longos processos de maturação econômica e concretização de promessas (sobretudo tecnológicas) quase utópicas, como aquelas que sugerem ser a Amazônia a região ideal para experimentalismos ainda abstratos do tipo "indústria $4.0+$ bioeconomia". Ou, ainda mais vaga, a sugestão de materializar-se uma "economia do conhecimento da natureza", cujo roteiro para seu surgimento sugere um tempo futuro 
longínquo, de improvável ocorrência (ABRAMOVAY, 2020).

Requer-se urgência no processo de mudança social e econômica e, por isso, qualquer proposta para a Amazônia precisa conter, pelo menos, algumas propostas específicas e realizáveis em curto prazo. Há uma expectativa por parte de comunidades indígenas, extrativistas, populações tradicionais, ribeirinhos, entre outros, quanto a esta presumida "fantástica repartição" de benefícios que, talvez, possa não se concretizar, gerando frustração social. Esta mesma assertiva é válida para o Protocolo de Nagoya (2010), que pode implicar em perdas, sobretudo para os grandes países agrícolas - referendado este ano, pela Câmara dos Deputados (LIMA, 2020).

Os recursos a serem explorados na biodiversidade precisam ser objetivamente nomeados, esse é o passo inicial. Quais são essas plantas ou animais, além do discurso futurista? Aqueles com potencial econômico mais relevante já foram transferidos e são eficientemente explorados em outros locais, no Brasil ou no exterior. São os casos, entre outros, da mandioca, cacaueiro, seringueira, guaranazeiro, pupunheira, jambu, urucuzeiro, etc. E há o outro lado da moeda - a biodiversidade exótica à Amazônia, em atividades como, entre outras, bovinos, bubalinos, juta, pimenteira do reino, mangueira, jambeiro, dendezeiro, soja, laranjeira, cafeeiro, eucalipto, etc. Diversos deles se instalaram e mantêm destaque produtivo em nível nacional.

Um caso simbólico e especial é o da imponente castanheira do pará, ainda sem ter sido objeto de biopirataria por ser árvore que exige longo tempo de frutificação. É planta que está exigindo muito mais pesquisa agronômica, em diversos aspectos, para permitir a sua exploração econômica. Como ela, diversas outras alternativas regionais podem ser exploradas - bacurizeiro, tucumanzeiro, pau rosa, cumaruzeiro, cupuaçuzeiro, açaizeiro, pirarucu, etc. Sem esta nomeação concreta, propostas potenciais permanecerão sob um discurso meramente abstrato. Mas estabelecidas prioridades e domesticadas visando a sua produtividade, são plantas e criações que seguirão o roteiro produtivo das demais, conforme a história da agropecuária em todo o mundo.

O pensamento mágico em torno da bioeconomia. Este é um dos temas mais polêmicos da listagem. A referência à promessa da "bioeconomia" destinada a "salvar a Amazônia" se tornou obrigatória em todas as manifestações, ainda que a sua definição (prática, objetiva) nunca seja apresentada. O fato espelha a natureza ainda relativamente obscura do que seria com precisão (conceitualmente) a bioeconomia e suas possibilidades, quando transformada em processos produtivos. Em consequência, relacionar tal expectativa a uma situação espacial e social tão complexa é desafio que, atualmente, parece ser ainda incontornável. A mal sucedida experiência do Centro de Biotecnologia da Amazônia (CBA), criado em 2002, é demonstrativa das 
imensas dificuldades de transformar "bioeconomia" e suas tecnologias em efeitos mensuráveis que transfiram benefícios à população local.

Similarmente ao antes apontado no tocante à "riqueza da biodiversidade", nesse caso emergem, novamente, as perguntas críticas: quais plantas e animais da biodiversidade seriam prioritários? Como e quando advirão as soluções concretas da bioeconomia? Como prevalecem respostas vagas e imprecisas, as urgências sociais, econômicas e ambientais dominantes no bioma amazônico não podem esperar. Desta forma, urge, sem dúvida, que mais pesquisas sejam realizadas para produzir luzes por esse caminho. Mas oferecer a assim chamada "nova bioeconomia", na atualidade, como um dos caminhos de maior potencialidade para o desenvolvimento mais sustentável da região não parece ser uma proposição razoável. ${ }^{4}$ É requerido, antes mesmo de propor a sua aplicação às realidades da região amazônica, estabelecer primordialmente, o que seria realmente esse caminho de convergência tecnológica intitulado "bioeconomia" e, posteriormente, analisar suas possibilidades práticas naquele contexto. A repetição desta promessa não passa de uma ilusão, pois esbarra na inexistência de atividades concretizáveis na atualidade.

Floresta em pé e desmatamento zero. São expressões usadas de forma parecida ou, às vezes, até mesmo como se fossem sinônimos. Os usos dessas expressões, portanto, são confusos e geram controvérsias. Normalmente, elas são utilizadas por grupos sociais radicalmente ambientalistas, para os quais a sociedade regional quase deixa de ser considerada e, menos ainda, a necessidade de se contar com uma estrutura econômica para mantê-la. São expressões, assim, que caracterizam um dos polos extremados do debate. Quase sempre, representados por grupos ambientalistas que conhecem pouco as realidades da região e muitos são externos ao Brasil, e suas propostas são ainda mais fantasiosas 5 .

Como citado acima, a defesa incondicional da "floresta em pé" não se sustenta logicamente e, talvez, nem mesmo politicamente - ou até moralmente. Afinal, seria ético defender a absoluta manutenção dos recursos da floresta e o não aproveitamento mais sustentável de suas possibilidades econômicas em uma região permeada por chocantes níveis de

\footnotetext{
${ }^{4}$ A "nova bioeconomia" pretenderia se valer de um conjunto de conhecimentos científicos e tecnológicos muito mais amplo e avançado, por exemplo, a biotecnologia, bioinformática, nanotecnologia, tecnologia da informação, biologia sintética, modificação genética de organismos vivos, clonagem e sequenciamento de DNA.

${ }^{5}$ Em junho de 2020, 17 ex-ministros da Fazenda e presidentes do Banco Central do Brasil reivindicaram "zerar o desmatamento", não apenas na Amazônia, mas igualmente no cerrado (sic). Afirmaram que "(...) o retorno financeiro do desmatamento (...) é baixo e certamente negativo quando se considera, além da biodiversidade e os serviços ambientais, o impacto reputacional sobre o país". Este documento está disponível em: https://economia.estadao.com.br/noticias/geral,carta-de-17-ex-ministros-e-ex-presidentes-do-bc-cobra-dogoverno-desmatamento-zero,70003363421
} 
pobreza? Esse seria um dilema sem solução, se a preservação do ambiente for alçada acima da defesa da vida humana. Entre essa difícil convergência, até mesmo um Ministro do STF julgou poder asseverar que o "caminho futurista", com a manutenção "em pé" da floresta seria o mais apropriado: “(...) abriu-se uma janela de oportunidade para estruturar uma 'terceira via' de desenvolvimento para a Amazônia, entre os dois extremos representados por manter a floresta intocada ou continuar a derrubá-la. Trata-se da bioeconomia da floresta", e sugeriu ainda a possibilidade de muitas (e misteriosas) surpresas, pois “(...) as plantas da Amazônia contêm segredos bioquímicos, como novas moléculas, enzimas, antibióticos e fungicidas naturais" (BARROSO e MELLO, 2020, p. 358).

Já a expressão "desmatamento zero" poderia se traduzir em argumentação razoável e construtiva para o debate sobre a Amazônia se for definida como "desmatamento (ilegal) zero", como muitos propõem e, inclusive, está contida nas metas climáticas do Brasil até 2030 (DESMATAMENTO ..., 2020). Ou seja, insistir no combate forte, rápido e eficaz às situações de desmatamento ilegal na região, mas aceitando o desmatamento legal que o Código Florestal permite em associação com a exploração mais sustentável da biodiversidade.

Há um fato empírico que atualmente vem se tornando comum na região, o qual, provavelmente, irá fortalecer, concretamente, a tendência de redução gradual do desmatamento. Diz respeito ao custo de desmatar e seu efeito na lucratividade do negócio, quando o Código Florestal permite que apenas um quinto da área da propriedade, no bioma, pode ser desmatado. Em estabelecimentos rurais de porte médio a grande, esta limitação, na prática, reduz o resultado financeiro do empreendimento, especialmente se a preservação dos restantes $80 \%$ da área impuserem custos financeiros, caso não seja mantida a cobertura vegetal, na forma de multas ambientais, vigilância ou outros gastos. Desta forma, se a legislação existente se tornar realmente efetiva na Amazônia, a restrição de uso da terra poderá desenvolver uma limitação econômica que contribuirá para restringir a intenção de desmatar grandes áreas, reduzindo o problema em sua totalidade. Citando, igualmente, que tem se ampliado as fontes de denúncias (por satélites, por exemplo, ou mesmo drones de fiscalização) e, desta forma, fortes ações de desmatamento ilegal, em áreas mais significativas, tendem a se reduzir com o tempo.

Como se apontará na terceira seção do artigo, a estratégia em relação ao tema dos desmatamentos (e queimadas) precisa ser encaminhada em três frentes distintas: com os grandes produtores (cuja tendência é de redução relativamente rápida), dirigida aos médios e pequenos (exigirá mais tempo, pois são práticas de cultivo, muitas vezes, culturalmente enraizadas) e, em especial, a terceira iniciativa demandará uma ação repressora forte em relação 
aos madeireiros.

A mutante história do desmatamento. Em especial para os observadores não moradores da região, a expressão mais assustadora da "destruição da região amazônica" é a imagem das queimadas e as visões, muitas vezes dantescas, de fotografias que evidenciam enormes áreas devastadas, pela mineração ou pelo desmatamento. Conflitos sociais com vítimas também caracterizaram a expansão da fronteira agrícola, especialmente nas bordas do sul e a leste do bioma amazônico. Mas esses foram típicos dos anos oitenta e parte da década seguinte. Já nesse século, o avanço da pecuária e da agricultura sobre terras de posseiros, comunidades indígenas e pequenas áreas ocupadas por famílias rurais pobres perdeu sua desenvoltura original e a contagem daqueles conflitos diminuiu sua força numérica (conforme os relatórios anuais da Comissão Pastoral da Terra).

$\mathrm{O}$ que tem sido relativamente ignorado, nos debates atuais sobre queimadas $\mathrm{e}$ desmatamentos, gerando acesas disputas de interpretação, é que tais fatos encobrem uma tendência de queda na história rural da região amazônica. Ocorreram algumas fases típicas, que foram sendo ultrapassadas com o passar dos anos e, mais recentemente, existem alguns "picos de devastação", em especial quando a ação do Estado e seus braços de contenção são enfraquecidos.

Mas são temas que ativam várias ideias equivocadas. No presente século, por exemplo, associar os indicadores de desmatamento da floresta densa com o plantio de soja é um contrassenso empírico facilmente comprovável. O plantio dessa cultura exige grandes extensões de áreas planas e sem tocos. Destocar uma área recém derrubada e queimada de floresta densa implicaria um custo proibitivo que não justificaria o investimento. Por isso, esta associação entre desmatamento e expansão dos cultivos de soja na região, quase certamente, não é verdadeira em praticamente nenhum caso específico.

Adicionalmente, ocorre o desmatamento da floresta densa com a saída de pequenos produtores de áreas já derrubadas e que vendem suas propriedades para ocupar novas áreas mais adiante. Uma prova empírica desta prática pode ser verificada com as áreas de soja ao longo da BR-163 (rodovia Cuiabá-Santarém), as quais acompanham o trajeto irregular determinado pelos roçados dos pequenos produtores e de fazendas com pastagens degradadas que foram posteriormente ocupadas com soja.

O mesmo não ocorre com os madeireiros. Esses usualmente não desmatam diretamente, mas induzem o desmatamento através das estradas abertas, criação de povoados e redução no custo para a formação de roçados. Os "sojeiros" têm interesse nessas áreas desmatadas, embora 
o valor da terra degradada tem valor superior às das terras cobertas de floresta densa neste processo de ocupação ou fazem por arrendamento. Mas exime, em compensação, da responsabilidade de crimes ambientais e diminui o custo de preparo da área.

Os desmatamentos e queimadas no período de 1970 a 2000 decorreram da expansão da fronteira agrícola ocasionada por pequenos, médios e grandes produtores, nessa ordem de escala e de tempo. Seus protagonistas, em sua maioria, foram sulistas que trouxeram a "agricultura moderna" e seus cultivos para a região. Os nordestinos e as populações nativas (caboclos, índios e quilombolas), na ampla maioria, desenvolveram a "agricultura de toco", que é a derrubada de pequenas áreas destinadas ao plantio de "roçados" concentrados em alimentos para a subsistência e pequeno excedente para comercialização.

Valoração de serviços ambientais e o mercado de carbono. A vitalidade ambiental do bioma amazônico, também mantendo uma economia regional sólida, que assegure bem estar à sociedade regional, interessa ao Brasil. Mas igualmente interessa ao restante do mundo, em face de sua crucial importância para o equilíbrio do clima do planeta. Seria esse um fato inquestionável, ainda que um reconhecimento pouco expresso, por enquanto, em termos monetários, seja pelos próprios brasileiros ou pela comunidade internacional. Não obstante doações financeiras, até generosas, de alguns países europeus, não se pode concluir que existe um verdadeiro "pagamento por serviços ambientais" à sociedade amazônica.

A inexistência de um sistema consolidado de iniciativas de pagamento por serviços ambientais decorre das diversas limitações em sua implementação. Tais pagamentos se tornam mais viáveis, usualmente, em situações mais críticas, quando um recurso essencial se torna demasiadamente escasso ou quando existem claras ameaças que sejam socialmente visíveis. Não sendo assim, há dificuldades práticas em sua implementação.

Quando já estruturado, o mercado de serviços ambientais ou de carbono é semelhante ao de soja ou milho, também segue suas curvas de oferta e demanda. À medida que a oferta de serviços ambientais for sendo ampliada (fábricas menos poluentes, reuso de água, entre outras possibilidades crescentes) os preços pagos pelos serviços ambientais, no longo prazo, serão decrescentes (WUNDER et al., 2008). Neste caso, as iniciativas seriam vítimas do seu próprio sucesso.

A ideia de valoração de serviços ambientais que assegure a permanência dos recursos hídricos para garantir o abastecimento de água e seu pagamento aos proprietários da terra já ocorre nos países desenvolvidos e há algumas tentativas no Brasil (HOMMA, 1993). Entretanto, em relação a amplitudes geográficas imensas, como aquelas cobertas pelos "rios voadores", 
surgem diversas perguntas complicadoras de grande complexidade operacional - quem iria pagar, como seria o pagamento e qual seria a racionalidade administrativa para transferir esses recursos para a sociedade amazônica?

Os créditos de carbono, por sua vez, envolvem inúmeros problemas práticos e, também, uma controvérsia ética. Esta última seria concretizada em decorrência da relativa paralisia das atividades econômicas na Amazônia em favor da manutenção de práticas ambientais (a intocabilidade da floresta e da "natureza em geral"). O caminho ideal para os habitantes da região seria a implementação de práticas produtivas mais sustentáveis que associem resultados econômicos com a preservação dos recursos naturais. Tais práticas, entretanto, no geral são ainda largamente embrionárias e sem comprovação acerca de sua economicidade final. Em síntese: falta ainda um amplo "menu de alternativas", ambientalmente desejáveis e economicamente recompensadoras.

A lógica defendida pelos países desenvolvidos é que os recursos provenientes do mercado de carbono e da valoração de serviços ambientais sejam administrados por ONGs a fim de controlar a produção destes serviços em comunidades indígenas, quilombolas e de pequenos produtores selecionados. Em um ambiente de escassez de recursos públicos a drenagem de recursos internacionais repassados por ONGs aprofundaria a separação entre o Estado e a sociedade civil regional. Em um contexto como esse, se prevalecer um precário sistema de controle governamental nos rincões mais afastados da região pode ocorrer a "internacionalização branca" da Amazônia.

A região amazônica e a agricultura moderna. Afirmado direta e cruamente-muito pouco existe, como padrão dominante que oriente as atividades agropecuárias, que se assemelhe à agricultura moderna na vasta e maior proporção do bioma amazônico. A exceção (notável) situase em sua borda sul e partes do leste paraense, nos quais esse padrão agrícola (soja, algodão, milho) tem se expandido. O Pará é um dos maiores produtores brasileiros de farinha de mandioca, mas os plantios centram-se nos pequenos estabelecimentos rurais com baixa tecnologia e formas ainda primárias de integração mercantil.

Desta forma, algumas das críticas à "agricultura moderna" (monocultura, uso intensivo de agroquímicos, da terra e da água) somente teriam algum significado concreto na região acima referida. Nas demais regiões onde existem atividades agrícolas e pecuárias, está se demandando, de fato, o contrário - mais incentivos, políticas e assistência técnica para se modernizarem, buscando maior produtividade e inserção nos mercados.

A promoção do desenvolvimento mais sustentável na região. A Amazônia experimentou 
várias fases de crescimento agrícola episódico nos últimos quatro séculos. Produtos da biodiversidade baseados no extrativismo que já tiveram grande peso na sua economia foram transferidos para outras regiões, constituindo-se em fontes de riquezas nesses novos locais ou, então, sofreram o seu esgotamento na própria Amazônia.

O aproveitamento da dotação dos recursos naturais permitiu que o extrativismo vegetal e animal tivesse um peso dominante na economia até 1960 , quando mais da metade do PIB regional decorria do uso desses estoques. O crescimento da pecuária e das lavouras nas áreas desmatadas de floresta densa, complementado com a extração madeireira, dominou a economia regional até o final da década de 1980, com grandes custos sociais e ambientais. Paralelamente, uma moderna agricultura centrada em grãos começou a despontar com a ocupação dos cerrados na borda sul amazônica, a partir do final da década de 1970, com reflexo posterior nas áreas degradadas desmatadas de floresta densa, com cultivos perenes, reflorestamento e a agroindustrialização.

A partir da década de 1990, o antes dominante processo de "pecuarização" vem sendo substituído pelo processo de "agriculturização", seguindo o movimento da expansão da soja, cuja dominância gaúcha foi perdida para o Paraná (em 1996) e, depois para o Mato Grosso (2000), este último estado também tornando-se o principal produtor de algodão (1998), milho (2013) e bovinos (2004). Em 2016, a área plantada com soja no Pará superou o tradicional e antigo cultivo de mandioca. Trouxe junto a lavoura de milho e outras que passaram a ocupar as áreas de pastagens degradadas, como o dendezeiro, cacaueiro e reflorestamento, os quais constituem as macroatividades agrícolas paraenses (HOMMA, 2017; 2019).

Tais transformações alçaram a Amazônia à posição de destaque mundial, sendo intensamente analisada e, quase sempre, problematizada. Surgiu uma encruzilhada para a região e o Brasil, em que novos desafios científicos e tecnológicos precisam ser enfrentados para conciliar o desenvolvimento agrícola com a conservação ambiental. Há necessidade de utilizar, de forma mais sustentável, o solo, a biodiversidade e a água, que compõem o ecossistema dominante, por meio de formas aperfeiçoadas de manejo florestal, da pecuária, da agricultura e da silvicultura. É que se propõe na seção seguinte deste artigo.

\section{Os caminhos possíveis}

Dada a citada heterogeneidade da região, a complexidade dos temas e a limitada extensão do artigo, decorre a impossibilidade de aqui se sugerir caminhos detalhados, incluindo 
as diversas facetas de um completo e abrangente "plano de desenvolvimento sustentável" para toda a Amazônia, discutido em profundidade. Desta forma, prioriza-se nesta seção algumas medidas destinadas a gerar renda e, ao mesmo tempo, preservar o meio ambiente sob uma configuração bem definida. Esse recorte são os aspectos que fariam parte, obrigatoriamente, do plano mais geral, mas com foco exclusivo no "desenvolvimento rural sustentável" a ser operado no bioma.

O conjunto dos elementos sugeridos prioriza o uso da ciência, a intensificação tecnológica, a renovação da assistência técnica, a regularização fundiária e a aplicação firme e sistemática dos marcos regulatórios existentes, especialmente o Código Florestal. Entre outros, esses seriam alguns dos imperativos básicos do que fazer. Insistindo-se que são ações passíveis de serem operacionalizadas com alguma celeridade e, por isso, aqui intituladas de "o caminho possível". A efetiva participação dos Estados na definição e execução das ações, o aproveitamento mais sustentável de áreas degradadas, a aceleração da transição florestal e a exploração equilibrada de potenciais inexplorados, como a piscicultura e a domesticação dos recursos da biodiversidade, são também outras atividades fundamentais discutidas a seguir.

Em consequência, são arroladas algumas macroações, imediatamente passíveis de concretização, as quais deveriam ser consideradas para a consolidação de um padrão agropecuário mais sustentável, mas igualmente promovendo a melhoria das condições de vida da população regional.

Aproveitar os "benefícios da destruição". Um importante esforço de pesquisa realizado nesta última década refere-se ao projeto Terraclass (TERRACLASS, 2020). As políticas enfocando desmatamentos e queimadas sempre tiveram o sentido, sobretudo, de combater a supressão da cobertura florestal, mas sem sinalizar as possibilidades sobre o uso da terra das áreas já desmatadas. Uma política consequente seria prover assistência técnica e outros incentivos aos produtores desejosos de manter a pecuária. São 38 milhões de hectares identificados como pastos limpos e a sua utilização mediante aumento da produtividade contribuiria para expandir a produção e a rentabilidade da pecuária, evitando assim a incorporação de novas áreas de floresta densa ou de vegetação secundária (SARAIVA, 2020). Como as pastagens na região usualmente duram de 10 a 12 anos (antes de renová-las), isto, significa, que anualmente, seria necessário recuperar dez por cento dessa área, algo em torno de 2 a 3 milhões de hectares (no mínimo), para evitar o risco de incorporação de novas áreas de vegetação secundária ou de floresta densa. Há 17 milhões de hectares com vegetação secundária e a política mais apropriada, 
nesse caso, seria manter a integridade dessas áreas para recompor as áreas de proteção permanente e de reserva legal.

As áreas com cultivos perenes, embora representando a vocação da Amazônia, ocupam menos de um milhão de hectares na região. Dada a existência de importantes mercados para esses cultivos, se deveria pelo menos duplicar nos próximos dez anos a exploração dessas atividades. ${ }^{6}$ Por outro lado, existem cerca de 10 milhões de hectares de pastagens degradadas na região. Nesse caso, a política seria dar um uso adequado para essas áreas, seja para a produção de cultivos anuais, semi-perenes, perenes, pastagens ou servir para recomposição de áreas de preservação permanente ou de reserva legal. Em síntese: esta é uma clara "janela de oportunidade", que uma ação concertada de políticas promoveria, com rapidez, não apenas o desenvolvimento de atividades econômicas, mas também uma forte recuperação ambiental.

Promover o nivelamento tecnológico. Assim como ocorre nas demais regiões do país, o gap tecnológico constitui um fator marcante na região amazônica em todos os segmentos produtivos. Mesmo em um contexto de degradação, existem produtores que improvisam soluções técnicas, ambientais e/ou de mercado, criando ilhas de eficiência, atingindo gradiente de sustentabilidade adequado (ARCE \& LONG, 2000). Esta interconexão se manifesta entre a percepção, a prática e os saberes dos produtores. A meta geral seria ampliar o uso dessas práticas como "patamar superior" a ser alcançado por um número muito maior de estabelecimentos. $\mathrm{O}$ uso dessas tecnologias já utilizadas pelos produtores mais eficientes seria uma maneira de contornar a escassez da oferta de tecnologia e ganhar tempo no contexto de curto e médio prazo.

Para vencer as atuais limitações tecnológicas presentes na região amazônica deve ser promovido um amplo esforço de identificação e transferência das tecnologias de sucesso das principais culturas e criações já em uso pelos pequenos, médios e grandes produtores rurais mais eficientes. A sua ampla disseminação pouparia tempo e produziria impactos imediatos, pois a geração de novas tecnologias, em geral, demora para serem disponibilizadas. Dessa forma há a necessidade de aliar um agressivo e renovado esforço de pesquisa agrícola e de extensão rural, sendo tais atividades cruciais para o sucesso desse "caminho" ora sugerido (BECKER, 2010; HOMMA et al., 2014a).

\footnotetext{
${ }^{6}$ Esta é uma observação de enorme importância prática. Uma estratégia agrícola para a região deveria privilegiar os cultivos perenes, sempre que possível. Em geral, são cultivos que ocupam apenas uma fração da área total plantada, quando comparados com os cultivos temporários, reduzindo a pressão sobre o uso da terra. E são plantas que melhor cumprem um "papel ecossistêmico". E áreas plantadas que saturam o mercado interno e atendem às exportações. O Brasil é o maior produtor de suco de laranja, com 700 mil hectares de área colhida, e de café, ocupando menos de dois milhões de hectares. Em comparação, as lavouras anuais utilizam áreas gigantescas, como a soja, que ocupa 35 milhões de hectares.
} 
Aumentar a produtividade dos cultivos e reduzir as áreas de pastos. É urgente reestruturar os programas de pesquisa e assistência técnica com alternativas que gerem renda, emprego e tenham mercado que beneficiem um milhão de produtores, a vasta maioria deles de pequeno porte econômico. Esse número de unidades de produção foi calculado recentemente, em acordo com o estudo realizado pela Embrapa Territorial, sobrepondo os dados do Cadastro Ambiental rural e os dados do IBGE (MIRANDA et alii, 2020a).

Os pequenos produtores na região amazônica, a despeito da sua baixa produtividade, são responsáveis pela metade da produção de pimenta do reino, grande parte da produção de cacau, hortaliças folhosas que abastecem os núcleos urbanos, açaí extrativo e manejado, pecuária leiteira, produção de farinha, frutas nativas e exóticas, entre outros. O estado do Pará é o maior produtor nacional de mandioca, abacaxi, cacau, dendê, pimenta do reino, bubalinos e outras atividades, normalmente ocupando entre a segunda e a quinta posição entre os estados maiores produtores.

As pastagens constituem a mais extensa área ocupada na Amazônia. São 38 milhões de hectares de pastos considerados bons e 10 milhões de hectares degradados. Sua produtividade, no geral, é extremamente baixa e nesse aspecto reside uma das grandes chaves para diminuir o desmatamento ilegal na região. O conhecimento empírico sobre as decisões de produtores rurais o demonstra cabalmente. Um grande número de pequenos produtores, por exemplo, com o objetivo primordial de produzir alimentos e pequenos excedentes destinados à comercialização, pode desmatar entre um a dois hectares todos os anos, mas usando esta nova área, como regra geral, somente durante duas safras e, depois, repetindo o ciclo em outra área adiante. Apenas a permanência por mais um ano na área desmatada, com poucas práticas agrícolas de sustentação produtiva para garantir o resultado agrícola, já asseguraria, no conjunto, pelo menos a redução em um terço do total do desmatamento verificado na região.

Como viabilizar esse caminho? Utilizando um conjunto de políticas para reduzir o custo de recuperação das áreas degradadas na Amazônia, que é relativamente muito mais elevado do que em outras regiões de produção agrícola do país. Esse é conhecimento existente, não implica em "planos futuristas" e produziria resultados concretos em prazos relativamente curtos.

É preciso domesticar os recursos da biodiversidade. Muitas das propostas que enfatizam a biodiversidade apontam o exemplo do açaí como sendo similar para todos os demais produtos da flora. Ao assim proceder, desconhecem as dimensões dos mercados, a extrema dispersão dos produtos na floresta e outros aspectos, como a perecibilidade ou a baixa produtividade da terra e da mão de obra. Usualmente, por falta de conhecimento empírico, se esquece que cada 
produto da biodiversidade apresenta um comportamento específico. O caso notório mais equivocado tem sido esta comparação entre "níveis de rentabilidade" do cultivo de açaí com os ganhos com a soja ou com a pecuária, um cotejo que, em termos empíricos, não faz o menor sentido. Como antes afirmado, se e quando existir o "aproveitamento econômico da biodiversidade", esse caminho somente se tornará realidade se ocorrer a domesticação dos recursos originais existentes, sobretudo entre plantas que apresentam potenciais de mercado. Fora desse caminho, estaria sendo oferecido apenas ilusões.

Novamente, sob tal aspecto desponta a urgência de esforços reestruturados em pesquisa agronômica consolidada, os quais produzam resultados com maior rapidez nos processos de identificação e domesticação das plantas mais promissoras, em acordo com as demandas de mercado. ${ }^{7}$

Promover a "revolução da piscicultura". Como é notório, a partir dos anos sessenta o Brasil iniciou uma grande transformação tecnológica na avicultura. A oferta de carne avícola suplantou a de carne bovina em 2007 e seus impactos ambientais são bem menores. O resultado não poderia ser mais expressivo: o país é atualmente o terceiro maior país produtor, mas o maior exportador, respondendo por pouco mais de um terço do mercado mundial.

É perfeitamente possível realizar revolução similar com a produção de pescado, o bioma amazônico sendo o seu contexto ideal. Esta atividade é ainda dependente de captura (54\% extrativa e o restante em criatórios), o que repete um padrão mundial, se for considerado o ano de 2017 (FAO, 2019). No Brasil, a produção de pescado corresponde a apenas um décimo da produção de carne de frango e a $15 \%$ do total da produção de carne bovina, se comparados os totais em 2017 (ABPA, 2020; CONAB, 2020). Na região, diversos estados já realizaram significativos avanços na produção de pescado, incentivando a construção de criatórios locais. A abundante disponibilidade de água sugere que a domesticação de peixes e quelônios que sejam potencialmente mais produtivos é também um dos caminhos mais promissores para a região. Poderá não apenas produzir mais proteína, como também ampliar a renda rural significativamente, sobretudo se os mercados internacionais também forem conquistados com o passar dos anos. Esta é uma "revolução produtiva" com potencial concreto, apenas aguardando as iniciativas necessárias para torná-la realidade.

\footnotetext{
7 Sob esse tema, contudo, destaca-se um aspecto de crucial importância prática. É preciso reconhecer que o adequado aproveitamento da biodiversidade, na Amazônia, esbarra na Lei 13.123 (2015) e no Decreto 8.772 (2016). São preceitos legais que se constituem em fortes entraves para as pesquisas com recursos genéticos. É urgente aperfeiçoá-los, adequando-os às realidades da investigação científica.
} 
Como apressar a transição florestal? Trata-se de um tema pouco debatido. O que caracterizaria tal transição? Reflete situações muito diferentes, quando comparados os países, pois são passagens históricas determinadas por fatores igualmente históricos. Combina a necessidade de usar a terra para fins produtivos e econômicos, de um lado, com a igual necessidade de manter a cobertura vegetal original, por tantas razões ambientais. A transição florestal, portanto, está diretamente relacionada, por exemplo, ao crescimento da população, as mudanças em dietas alimentares, à elevação da renda, à expansão dos mercados, entre diversos outros fatores. Assim como, em anos mais recentes, às preocupações sociais ambientais e, em especial, às mudanças climáticas. Não existe, portanto, um roteiro único para ocorrer a transição florestal, mas cada sociedade, em certo momento de sua história, decide que a combinação acima referida seria "a melhor para o país" e, a partir desse período, se alcança alguma estabilidade entre o uso da terra e a cobertura florestal remanescente.

Quando ocorrerá a transição florestal no Brasil, em geral, ou na Amazônia, em particular? O Código Florestal aprovado é um decisivo balizador, mas será determinante? Não é possível prever, podendo ser em prazo mais curto ou, então, se persistirem desentendimentos sociais, se estenderá por muitos anos. É por esta razão que este artigo reivindica a adoção de um rápido "caminho possível", descartando as tantas utopias ora apresentadas. Pois assim, articulando alternativas tecnológicas e econômicas viáveis, este ponto de relativo equilíbrio representado pela transição florestal poderá ser logo alcançado.

Deve se enfatizar, igualmente, que essa passagem tem um limite físico, a partir do qual, afetará o regime de chuvas e, portanto, a produção agrícola e outras possibilidades produtivas. Foram desmatados até o momento (2019) cerca de 19-20\% da Amazônia Legal (aproximados 78 milhões de hectares), o que representa uma área superior a três vezes o estado de São Paulo. Não é possível reverter toda a área derrubada em vegetação secundária ou em floresta novamente. A meta razoável e realista seria reconverter em cobertura florestal entre 10 a 15 milhões de hectares, mediante a recuperação do passivo ambiental (APP e ARL), reflorestamento e cultivos perenes.

O desafio do Novo Código Florestal. Enraizar o Código nas práticas sociais e institucionais é atualmente um dos maiores desafios para o futuro próximo da agropecuária brasileira. Apesar de seus limites, foi o acordo possível, aprovado em 2012, e, também, representou consideráveis avanços e, assim, sua concretização efetiva é essencial. Se realmente implementado, poderá corrigir erros do passado (recuperação de cursos de água e áreas degradadas), mas também 
assegurar a resiliência futura dos recursos ambientais do nosso vasto interior. Para isso, será preciso ter "mão de ferro", nos limites da lei, para garantir a sua efetivação prática.

Para os produtores na Amazônia o Código impõe desafios adicionais. O principal deles reside na competição com cultivos e criações também realizadas em outras regiões produtoras. Se existe a imposição do Código Florestal, na Amazônia, de desmatar somente um quinto da área, em cada propriedade, o cálculo é matemático - em tese, será necessário quadruplicar a produtividade para manter algum nível de competição com os produtos oriundos de outras regiões do país. Poderão existir vantagens locacionais, mas este será um muro quase intransponível para os produtores da região. Ante esta comparação sobre as exigências do Código, bastaria citar que a Bahia é o maior produtor brasileiro de guaraná, São Paulo, Bahia e Santa Catarina lideram no plantio de pupunheiras e somente em São Paulo, oito municípios produzem muito mais borracha do que em toda a região Norte.

Por esta razão, as demais ações sugeridas nesta seção do artigo se tornam ainda mais urgentes e relevantes. Se todas as sugestões forem encaminhadas concretamente, poderia se abrir um caminho promissor para a região, pois a rota inteligente para o desenvolvimento rural sustentável na Amazônia será ancorar-se em sua espetacular e (ainda) particular biodiversidade, estabelecendo uma nova agricultura tropical, da mesma forma que fizeram sucesso algumas plantas amazônicas no Sudeste asiático e no continente africano. Para tanto, como antes enfatizado, os caminhos aqui citados, entre os quais a domesticação agronômica, são urgentes, o que também exige atividades de pesquisa e extensão rural fortemente reestruturadas na região. Este é o caminho não apenas possível, mas o sensato.

\section{Considerações finais}

Promover um efetivo desenvolvimento rural na Amazônia depende da criação de alternativas tecnológicas e econômicas realmente sustentáveis para a região. Depende também de uma nova e sólida estrutura de governança entre os estados e o Governo Federal, em particular para combater com firmeza as corriqueiras ilicitudes ora existentes - desmatamento ilegal, queimadas, extração madeireira predatória, garimpos, narcoeconomia, contrabando de armas e de matérias vivas da flora e da fauna.

A força inercial do processo de desmatamento e das queimadas não será interrompida abruptamente para alcançar o desmatamento zero. De fato, o grande erro governamental com 
respeito à manutenção dos indicadores de redução recente dos desmatamentos (2004-2015) foi a falta de políticas concretas visando a utilização das áreas já desmatadas.

Promover a bioeconomia também fará parte do caminho a seguir, mas é preciso mais clareza sobre suas possibilidades. A chamada "velha bioeconomia" sempre existiu na Amazônia, como em qualquer outro lugar do mundo. Mas a concretude da "nova bioeconomia" é ainda muito limitada pela complexidade das tecnologias, pelo seu maior custo relativo ou a reduzida disponibilidade de assistência técnica, além de ser principalmente voltada para o segmento bioindustrial, entre outros fatores limitadores. Reconhecida a necessidade de enfrentar esses desafios para implantar a "nova bioeconomia", cabem outras medidas complementares. Por exemplo, domesticar elementos da flora e da fauna que apresentam conflitos entre a oferta e a demanda e a inclusão de novos recursos da biodiversidade, promovendo a ampliação dos mercados.

O controle da expansão da pecuária de baixa produtividade é igualmente essencial na Amazônia. O seu avanço descontrolado favorece a contínua incorporação de novas áreas, com a venda de madeira e a formação de novos roçados e pastos nas regiões mais remotas (onde não há a fiscalização do Estado). Como em outras regiões modernizadas da agricultura brasileira, é necessário que na Amazônia o "crescimento via expansão da área plantada" mude para o "crescimento conduzido pela produtividade". Essa modernização produz não só o aumento da produção como também a "consciência ambiental" (preservar a água, o meio ambiente, controlar a erosão) dos próprios agricultores.

Da mesma forma, deve-se explorar de forma prioritária a grande demanda de produtos hortifrutigranjeiros, pequenos animais, pescados, arroz e farinha, entre outros, em mercados locais estratégicos, como os das regiões metropolitanas de Manaus e Belém, Santarém e outras cidades de maior porte.

Sob o federalismo vigente, é fundamental que o planejamento e a execução das ações sejam desenvolvidos sob uma ótica estadual ao invés de adotar um enfoque geral e exclusivamente federal para a Amazônia. O "caminho possível” acima apresentado, juntamente com outras políticas já conhecidas e provadas, instituídas em harmoniosa cooperação entre o Estado federal e os estados e municípios, também envolvendo fortemente a pesquisa agrícola e a assistência técnica, finalmente poderão arquitetar um caminho viável e realista para o desenvolvimento sustentável do bioma Amazônia. 


\section{Referências}

ABPA. Aves. Disponível em <https://abpa-br.org/mercados/>. Acesso em 04 ago. 2020.

AGROANALYSIS. Desmatamento ilegal: separando o joio do trigo. In: Agroanalysis, v.40, n.8, p.11, ago. 2020.

ARCE, A. and LONG, N. Anthropology, Development and Modernities. New York: Routledge, 2000. 232p.

BRUNDTLAND, G. H.; KHALID, M.; AGNELLI, S.; AL-ATHEL, S. A.; CHIDZERO, B.; FADIKA, L. M.; HAUFF, V.; LANG, I.; MA, S.; BOTERO, M. M.; SINGH, N. Our common future. Oxford: Oxford University Press, 1987. 383p.

CONAB. Análise Mensal: Carne Bovina. Abril/2019. Disponível em:

https://www.conab.gov.br/info-agro/analises-do-mercado-agropecuario-eextrativista/analises-do-mercado/historico-mensal-de-carne-bovina. Acesso em 04 ago. 2020.

FAO. FAO Yearbook. Fishery and Aquaculture Statistics 2017. Rome: FAO, 2019.

FEARNSIDE, P.M. Brazil's Cuiabá-Santarém (BR-163) Highway: The environmental cost of paving a soybean corridor through the Amazon. In: Environmental Management, v.39, n.5, p: 601-614, 2007. (https://doi.org/10.1007/s00267-006-0149-2)

GOODLAND, R.J.; IRWIN, H.S. Amazon jungle: green hell to red desert? Amsterdam: Elsevier, 1975. 155p.

HOMMA, A.K.O. 'Agriculturização' na Amazônia: Conflitos e Oportunidades. In: SILVA, L. de J. de S.; PINHEIRO, J.O.C.; MUNIZ, A.W. (Ed. Tec.). Pesquisa e agricultura familiar: intercâmbio de ações e conhecimentos para transferência tecnológica na Amazônia. Manaus: Embrapa Amazônia Ocidental, 2019. p. 13-41.

HOMMA, A.K.O. A terceira natureza da Amazônia. In: Revista Paranaense de Desenvolvimento, Curitiba, v.38, n.132, p.27-42, jan./jun. 2017.

HOMMA, A.K.O. Amazônia: a civilização do fogo. In: ALVES, R.N.B.:\& MODESTO JÚNIOR, M. de S. (Eds.). Roça sem fogo: da tradição das queimadas para a agricultura sustentável na Amazônia. Brasília: Embrapa, 2019. p.11-33.

HOMMA, A.K.O. Os países desenvolvidos devem pagar pela preservação da Amazônia? In: Pará Desenvolvimento, Belém, n.28, p.:6-9, jan./jun. 1993.

INPA. Metodologia utilizada nos projetos PRODES e DETER. Campinas: INPA, agosto, 2019

KINOSHITA, D. L. Uma estratégia para inserção soberana da América Latina na economia globalizada: a questão amazônica. Disponível em:

<http://www.pps.org.br/2008/06/04/noticia-97118/>. Acesso em: 31 mar. 2016.

LIMA, J.E.C. Protocolo de Nagoia: dez questões fundamentais para entender esse acordo internacional sob a perspectiva brasileira. Disponível em

<https://ambitojuridico.com.br/cadernos/direito-ambiental/protocolo-de-nagoia-dezquestoes-fundamentais-para-entender-esse-acordo-internacional-sob-a-perspectivabrasileira/>. Acesso em 11 ago. 2020.

MIRANDA, E.E, et alii. 2020a. Contribuições do geoprocessamento à compreensão do mundo rural e do desmatamento no bioma Amazônia. In: Colóquio - Revista do Desenvolvimento Regional, v. 17, n. 1, p.16-34, jan./mar. 2020 
MIRANDA, E.E.; MARTINHO, P.R.R. e CARVALHO, C.A. Nota técnica sobre queimadas, desmatamentos e imóveis rurais no bioma Amazônia em 2019. Campinas: Embrapa Territorial, julho, $2020 \mathrm{~b}$

NOBRE, A.D. O futuro climático da Amazônia: relatório de avaliação científica. São Paulo: Articulação Regional da Amazônia, São José dos Campos: INPE, 2014.

NOBRE, I. \& NOBRE, C. Projeto 'Amazônia 4.0': Definindo uma Terceira Via para a Amazônia. In: Futuribles, São Paulo, n.2, p.7-20, set. 2019.

PIVETTA, M. Novas aves da Amazônia. In: Pesquisa FAPESP, n.2017, p.18-23, mai. 2013.

SARAIVA, M.B.; FERREIRA, M.D.P.; CUNHA, D.A. da C.; DANIEL, L.P.; HOMMA, A.K.O.; PIRES, G.F. Forest regeneration in the Brazilian Amazon: Public policies and economic conditions. In: Journal of Cleaner Production, v.269, p.1-11, 1 Oct. 2020.

TERRACLASS 2004 a 2014. Mapeamento do uso e da cobertura da terra na Amazônia Legal brasileira. Disponível em:

$<$ http://www.inpe.br/cra/projetos pesquisas/arquivos/TerraClass 2014 v3.pdf $>$. Acesso em 03/08/2020.

WUNDER, S.; BORNER, J.; RUGNIZ, M.; PEREIRA, L. Pagamentos por serviços ambientais: perspectivas para a Amazônia Legal. Brasília: MMA, 2008. 136 p. (Série Estudos, 10). 